\title{
PERADABAN ISLAM DI ANDALUSIA (PERSPEKTIF SOSIAL BUDAYA)
}

\author{
Refileli \\ Fakultas Ushuluddin, Adab dan Dakwah IAIN Bengkulu \\ Jalan Raden Fatah Pagar Dewa Bengkulu \\ refileli.agil@gmail.com
}

\begin{abstract}
Islamic Culture in Andalusia (Social Culture Percpects). From the side of science, not only from among the Muslims themselves, the western people have admitted, that most of the fundamentals of science are born by Muslim scientists. Similarly, the era of the rise of Europe that can not be separated from the influence of the development of science in the Islamic world, where the students from Europe have been sent to Baghdad and Cordova to explore the science there. In the fields of Islamic science, the development of Arabic literature and language was widespread in the Umayyad period. In addition also born the great Ulama-ulama. Therefore, re-examining the history of the Umayyads is important, for today's civilization is part of an endless chain of history and by examining and understanding the history of Islamic civilization during the Second Umayyad period in Andalusia we will be able to map the history of Islamic civilization part of the evolutionary chain to the present.
\end{abstract}

Keywords: Islamic, Andalusia, Culture.

Abstrak: Peradaban Islam di Andalusia (Perspektif Sosial Budaya). Dari sisi ilmu pengetahuan, tidak hanya dari kalangan muslim sendiri, orang-orang baratpun telah mengakui, bahwa sebagian besar dasar-dasar ilmu pengetahuan di lahirkan oleh para ilmuwan muslim. Begitu pula dengan masa kebangkitan Eropa yang tidak lepas dari pengaruh perkembangan ilmu pengetahuan di dunia Islam, dimana para pelajar-pelajar dari Eropa telah dikirim ke Baghdad dan Cordova untuk menggali ilmu pengetahuan di sana. Di bidang-bidang ilmu keIslaman, perkembangan sastra dan bahasa Arab secara meluas terjadi pada masa Umayyah. Selain itu lahir pula Ulama-ulama besar. Oleh karena itu, meneliti kembali sejarah Bani Umayyah menjadi penting adanya, sebab peradaban masa kini merupakan bagian dari rantai sejarah yang tidak putus dan dengan meneliti dan memahami sejarah peradaban Islam pada masa Bani Umayyah II di Andalusia kita akan dapat memetakan rentetan sejarah peradaban Islam yang merupakan bagian dari rantai evolusi hingga masa kini.

Kata Kunci: Islam, Andalusia, Budaya.

\section{Pendahuluan}

Islam pada periopde klasik, di zamaan keemasannya, dapat melebarkan ekspansinya sampai ke daerah yang paling jauh disebelah barat, yaitu ke wilayah Andalusia, yang sekarang dinamakan Spanyol. Perkemabangan Islam di Spanyol sedemikian rupa sehingga kebudayaan Islam Spanyol setingkat dengan di dunia Islam bagian Timur.

Ibu kota Islam Spanyol adalah Cordova, tempat keduduakan khalifah, kota megah yang agaknya lebih mengagumkan dari pada Bagdad. Islam
Spanyol hidup aman sentosa berabadabad lamanya. Ia membatasi daerah Nasrani di pegunungan sebelah utara negeri itu.

Tetapi ketika tenaga bangsa Arab mulai lemah, orang Nasrani mendesak orang Islaam ke arah selatan. Dalam pertempuran Las Navas de Tolosa pada tahun 1213 M. hancurlah Islam Spanyol. Sesudah itu tidak merupakan persoalan lagi bagi orang Nasrani yang tengah dalam kemenangan itu untuk merebut kedudukan-kedudukan Islam Spanyol lainnya. ${ }^{1}$ 


\section{Masuknya Islam ke Andalusia}

Sebenarnya semenjak abad $1 \mathrm{H}$, tentara Islam sudah mendarat di sana atas undangan dan permintaan dari Count Julian, Gubernur Spanyol di Ceuta, untuk menghalau panglima Roderick (Rodrigo) yang merampas kekuasaan dari tangan Raja Gouthia yang bernama Vitiza pada tahun $710 \mathrm{M}^{2}$. pada waktu itu Islam dalam kekuasaan Dinasti Umayyah, yakni khalifah keenam, Khalifah Al-Walid bin Abdul Malik (Al-Walid I) tahun 86 H/705 M. kesempatan permintaan itu tidak disiasiakan dan diamajukan kepada Gubernur Islam di Afrika Utara, yakni Musa bin Nushair, demi menentang kezaliman dan membantu keadilan. Gubernur Musa memperkenankan perminataan itu dengan mengirimkan tentara Islam di bawah pimpinan Thariq bin Ziyad untuk mengadakan penyerangan ke Andalusia.

Thariq kemudian menyeberang Selat yang terdapat antara Maroko dengan benua Eropa dan mendarat disuatu tempat yang kemudian dikenal dengan namanya Gibraltar (Jabal Thariq) ${ }^{3}$. Pasukan Thariq bin Ziyad berhasil mengalahkan Raja Roderick. Kemenangan inipun menjadi modal baginya untuk menaklukkan kota-kota lainnya, seperti Cordova, Archedonia, Malaga, Elvira dan akhirnya Toledo, yakni pusat kerajaan Visigoth ${ }^{4}$.

Sementara daulah Bani Umayyah di Damaskus sedang terjadi kekacauan politik, yakni Bani Umayyah dikejar-kejar dan disapu bersih oleh Bani Abbas, ada seorang di antara mereka yang dapat mealarikan diri dari bawah kematian, yaitu Abdurahman ad-Dakhil (yang masuk, sebab dia masuk ke Andalusia) ${ }^{5}$.
Dan dia ditemani ajudannya bernama Baddar. ${ }^{6}$

Ketika itu ke-amir-an di Andalusia berada di tangan Yusuf bin Abdurahman Al-Fihr (129 H/746 M - 138 H/756 M) dari Bani Muzar.

Abdurahman bin Mu'awiyah mendapat tantangan dari penguasa Andalusia. Namun akhirnya berhasil mengambil alih kekuasaan, karena di Andalusia saat itu sedang ada perselisihan di antara akabila-kabila, khusunya masalah intern kabilah Arab dari Qais dan Yaman yang tidak setuju terhadap kepemimpinan Yusuf bin Abdurrahman Al-Fihr. Semenatara itu pula Abdurrahman bin Mu'awiyah juga mendapat dukungan dari warga Ummayyah yang telah tinggal di Addalusia, disamping dukungan dari suku Yaman yang sedang bertikai dengan yusuf bin Abdurrahman Al-Fihr?.

Adapun ibu kota Andalusia adalah Cordova yang menjadi saingan setaraf bagi Bagdad sebagai pusat peradaban Islam. Cordova di Barat dan Bagdad di Timur.

\section{Perkemabangan Pertadaban Islam di Andalusia}

Selama Islam berada di Andalusia, yakni $\pm 7,5$ abad, Islam telah memainkan peranan yang sangat besar dan dapat membuat sejarah panjang yang dilalui umat Islam di Andalusia sebagai yang paling mengesankan. Pemerintah Amawiyah merupakan inti dan jantungnya yang telah menghayati dan menghidupkan kebudayaan dan peradaban besar. Pada umumnya ahli sejarah membagi zaman yang panjang itu dalam 6 periode, yakni : 


\section{Periode pertama (711-755)}

Anadalusia pada periode ini dibawah pemerintahan para wali yang diangkat oleh khalifah BaniUmayyah yang berpusat di Damaskus. Stabilitas politik negeri Spanyol pada waktu itu belum tercapai secara sempurna karena adanya gangguan-gangguan yang masih terjadi, baik yang datang dari dalam maupun dari luar.

Gangguan dari dalam berupa perselisihan antara etnis dan golongan serta perbedaan pandangan antara khalifah di Damaskus dan Gubernur di Afrika Utara uyang berpusat di Kairawan. Masing-masing mengaku bahwa merekalah yang berhak menguasai daerah Spanyol inis.

Gangguan dari luar datang dari sisasisa musuh Islam di Spanbyol yang bertempat tinggal di daerah-daerahdaerah pegunungan yang memang tidak pernah tunduk kepada Pemerintah Islam. Pada periode ini Islam Spanyol belum memasuki kegiatan pembangunan dibidang peradaban dan kebudayaan. Periode ini berakhir dengan datangnya Abdurrahman ad-Dakhil ke Spanyol pada tahun $138 \mathrm{H} / 755 \mathrm{M}$.

\section{Periode Kedua (755-912 M)}

Andalusia pada periode ini berbeda di bawah pemerintahan seiorang yang bergelar Amir (panglima atau gubernur) yang bernama Abdurrahman yang datang dari jauh, dan Timur, pada tahun 138 H / $755 \mathrm{M}$, lalu mendirikan pemerintahan otonom yang tidak ada hubungannya dengan pemerintahan pusat Abbasiyah di Bagdad.

Pada periode ini umat Islam Spanyol mulai memperoleh kemajuan-kemajuan, baik dalam bidang politik maupun dalam bidang peradaban, antara lain :

1. Abdurrahman ad-Dakhil mendirikan masjid Cordova dan sekolah-sekolah di kota-kota besar Spanyol.

2. Hisyam dikenal berjasa dalam menegakkan hukum Islam.

3. Hakam dikenal sebagai pembaharuan dalam bidang kemiliteran.

4. Abdul Rahman al-Ausath dikenal sebagai penguasa yang cinta ilmu dan yang ditekuni adalah pemikiran filsafat. ${ }^{9}$

Walaupun demikian, pada pertengah abad ke-9 stabilitas negara terganggu dengan munculnya gerakan Kristen fanatik yang mencari kesyahidan. Namun gerakan ini tidak mendapatkan dukungan dari gereja Kristen lainya di spayol., karena pemerintah Islam mengembangkan kebebasan beragama.

Justru gangungan politik yang paling serius pada priode ini datang daru imat Islam sendiri., seperti golongan pemberontak di Toledo pada tahun $825 \mathrm{M}$. membentuk negara kota yang berlangsung selama 80 tahun. Yang terpenting di antaranya adalah pemberontakan yang dipimpin oleh Hafshun dan anaknya yang berpusat dipengungunagn dekat Malaga. ${ }^{10}$

Priode ketiga (912-1013 M)

Pada priode ini berkembang pemerintah abdul Ar-Rahman III yang bergelar Ar-Nasir, sampai munculnya raja -raja kelompok yang dikenal dengan Muluk al-Thawaif. Pemerintah pada priode ini mengunganakan gelar khalfah. Gelar khalifah ini bermula dari berita yang sampai kepada abdurahman III yang mendengan bahwa Al-Muktadir, kholifah Daulah Abbasiyah di Bagdad 
meninggal dunia dibunuh oleh pengawalnya sendiri. Menurut Abdurahman III, ini merupakan saat yang tepat untuk memekai gelar khalifah yang telah hilang dari kekuasaan Bani Umayah selama \pm 150 tahun.

Pada priode ini umat Islam mencapai puncak kemauan dan kejayaan yang menyayingi kejayaan daulah Abbasiyah di bagdad, seperti :

1. Abd al-Rahman al-Nasir mendirikan universitas Cordova. Perpustakaan memiliki ribuan koleksi buku.

2. Hakam II juga seorang kolektor buku dan pendiri perpustakaan. Pada masa ini masyarakat dapat menikmati kesejateraan dan kemakmuran, dan pembangunan kota berlangsung cepat.

Awal dari kehancuran khalifah bani Umayyah di Spayol adalah ketika Hisyam naik tahta dalam usia 11 tahun. Oleh karena itu kekuasaan aktual berada ditangan para penjabat.

Pada tahun 981 M. Khalifah menunjuk Ibn Abi amir sebagai pemegang kekuasaan secara mutlak, sementara dia sebagai seorang yang ambisius berhasil menancapkan kekuasaannya dan melebarkan wilayhnya kekuasaan Islam dengan menyingkirkan rekan-rekan dan saingan-sainganya. Atas keberhasilankeberhasilannya ia mendapat gelar AlManshur Billah. Ia wafat pada tahun 1002 M. dan diganti oleh anak nya Al-Mazaffar ayang masih dapat mempertahankan keunggulan kerajaan. Akan tetapi setelah wafat pada tahun 1008 M. ia digantikan oleh adiknya yang tidak memiliki kualitas bagfi jabatan itu. Dalam beberapa tahun saja negara dilanda kekacauan dan akhirnya kehancuran total.
Pada tahun 1009 M. khalifah mengundurkan diri dan beberapa orang yang dicoba untuk menduduki keadaan. Pada tahun 1013 M. jabatan, khalifah-pun dihapuskan dan Spanyol sudah terpecah dalam negara-negara kecil yang berpusat di kota-kota tertentu. ${ }^{11}$

\section{Periode keempat (1031-1086 M)}

Spanyol pada periode ini terpecahpecah lebih dari 30 negara kecil dibawah pemerintahan raja-raja golongan atau AlMulukut Thawaif (dianasti-dinasti kecil) antara lain :

1. Bani Abbad di Sevilla

2. Bani Hud di Saragosa

3. Bani Zun Nun di Toledo

4. Bani Ziri di Granada

5. Bani Hammud di Cordoba dan Malaga. ${ }^{12}$

Pada periode ini umat Islam Spanyol kembali memasukimasa pertikaian intern. Anehnya, kalau terjadi perang saudara, ada diantara pihak-pihak yang bertikai meminta bantuan kepada raja-raja Kristen. Melihat keadaan itu orang-ortang Kristen mengambil inisiatif penyerangan. Meskipun kehidupan politik tidak stabil, namun kehidupan intelektual terus berkembang.

\section{Periode kelima (1086-1248 M)}

Pada periode ini walau Islam Spanyol masih terpecah dalam beberapa negara, tetap[I terdapat satu kekuatan yang dominan, yaitu kekuasaan dinasti Muwahhidun (1146-1235). ${ }^{13}$

Dinasti Murabithun pada mulanya adalah sebua gerakan agama yang didirikan oleh Yusuf Ibnu Tasyfin di Afrika Utara. Ia masuk ke Spanyol atas undangan penguasa-penguasa Islam di sana yang tengah memikul beban berat dalam mempertahankan negara dari 
serangan-serangan orang-orang Kristen. Pada tahun $1086 \mathrm{M}$ berhasil mengalahkan pasukan Castilia.penguasa-penguasa sesudah Ibn Tasyfin adalah raja-raja yang lemah dan pada ttahun 1143 M, kekuasaan dinasti ini berakhir, baik di Afrika Utara maupun di Spanyol dan digantikan oleh dinasti Muwahhidun.

Dinasti Muwahhidun. Didirikan oleh Muhammad Ibnu Tumart (W. 1128) dan dinasti ini datang ke Sapanyol di bawah pimpinan Abd Al-Mun'im. Pada tahun 114 dan 1154 M. lota-kota muslim penting, Cardova, Almeria dan Granada jatuh kebawag kekuasaanya. Untuk jangka bebarapa dekade, dinasti ini mengalami banyak kemajuan, sehinggakekuatan-kekuatan Kristen dapat dipukul mundur. Akan tetapi tidak lama setelah itu mengalami keambrukan dari perlawanan tentara Kristen. Akibat kekalahan ini Muwahhidun meninggalkan Spanyol dan kembali ke Afrika Utara tahun 1235 M. keadaan Sapanyol kembali berada di bawah penguasa-penguasa kecil yang membuat orang-orang Kristen mudah untuk mengadakan penyeranganpenyerangan. Tahun $1238 \mathrm{M}$. Cordova jatuh ke tangan penguasa Kristen. Tahun 1248 M. Sevilla pun dapat dikuasai. Akibatnya seluruh Spanyol kecuali Granada lepas dari kekuasaan Islam. ${ }^{14}$

\section{Periode keenam (1248-1492 M)}

Tinggalah Granada yang masih dalam kekuasaan Islam di bawah pimpinan dinasti bani Ahmar (1232-1492 M). Peradaban pada periode ini mengalami kemajuan kembali, namun hanya diwilayah yang kecil. Akan tetapi pertahanan Islam di Spanyol ini berakhir karena perselisihan orang-orang istana dalam memperebutkan kekuasaan.
Abdu Abdullah Muhammad meras tidak senang kepada ayahnya karena menunjukanaknya yang lain sebagai penggantinya menjadi raja. Kemudian dia memberontak dan berusaha merampas kekuasaan. Dalam pemberontakan itu, ayahnya terbunuh dan digantikan oleh Muhammad Ibn Sa'ad. Kemudian Abu Abdullah meminta bantuan kepada Ferdinand dan Isabella untuk menjatuhkannya. Dua penguasa Kristen ini dapat mengalahkan penguasa yang sah dan Abu Abdullah naik tahta.

Dengan adanya itu, ferdinand dan Isabella mempersatukan kekuatan untuk merebut kekuasaan terakhir Islam di Spanyol.15 Pada tahun 1492 M. Islam mengaku kalah dan kembali ke Afrika Utara. dengan demikian berakhirlah kekuasaan Islam di Spanyol.

Abu Abdilla bersama sanak keluarganya dikeluarkan dari Andalusia dan menyerahkan kerajaan yang didirikan oleh nenek moyangnya dengan jiwa dan pedangnya kepada musuhnya. ${ }^{16}$

\section{Pusat-pusat peradaban Islam di Andalusia}

Ketika Islam Jaya di Andalusia, maka terdapatlah pusat-pusat peradaban Islam baik yang bersifat fisik maupun yang bersifat ilmu pengetahuan. Termpattempat tersebut antara lain:

\section{Taledo}

Menurut Musyrifah Sunanto, seperti yang disampaikan dalam perkuliahan, di Toledo terdapat banyak tempat-tempat untuk ilmu pengetahuan, yaitu:

1. Perguruan Baitul Hikmah

2. Kutubul Hannah, untuk menampung terjemahan-terjemahan ilmu pengetahuan. 
3. Rumah sakit, laboratorium dan istana. ${ }^{17}$

\section{Cordova}

Cordova merupakan ibu kota Spanyol. Setelah Spanyol/Andalusia menjadi wilayah Islam, maka bangunannya diberi gaya seni bangunan Islam. Sehingga Andalusia kemudian terkenal dengan kota-kotanya yang indah, masjid-masjid yang cantik, demikian juga taman-taman dan rumah-rumah rakyatya. Harun Nasution mengatakan bahwa, Cordova merupakan pusat kebudayaan Islam yang penting di Baragt, sebagai tandingan Bagdad di Tiur. Kalau di Bagdad terdapat Bait Al-Hikmah serta $\backslash$ Madrasah Nizamiah dan di Cairo terdapat Al-Azhar serta Dar Al-Hikmah, di Cordova terdapat Universitas Cordova sebagai pusat ilmu pengetahuan yang didirikan oleh Abd Al-Rahman III (929 M$961 \mathrm{M}) .18$

Selain itu di Cordova terdapat kotakota kecil mungil yang menjadi satelitnya, antara lain:

1. Al-Qashrul Kabir (Kota Raja)

Al-Qashrul Kabir adalah salah satu pertanda zaman yang sangat mengagumkan. Kota raja tersebut dibangun oleh Abdurrahman ad-Dakhil pada pertengahan abad ke II H. Di tengah-tengah kota raja tersebut di bangun sebanyak 430 gedung yang diantaranya terdapat istana-istana yang besar dan agung yang masing-masing diberi nama khusus, seperti Kamil Mujaddid, Haair, Raudhah, Ma'syuq, Mubarak, Rasyiq, Surur dan Badi. ${ }^{19}$

2. Az-Zahra (Kota Az-Zahra)

Qashru Az-Zahra ini dibangun oleh Khalifah Nashir pada tahun $325 \mathrm{H}$. Dalam kota Zahra terdapat sebuah masjid besar, istana-istana dan tamantaman indah, bahkan pilarnya ada 4300 buah yang sebagiannya didatangkan dari Roma dan Tunisia.

\section{Zahira}

Zahira adalah kota yang didirikan oleh Khalifah Mansur bin Abi Amir. Zahira ini digunakan sebagai benteng yang kuat untuk mempertahankan diri dari serangan musuh.

\section{Granada $^{20}$}

Granada merupakan kota nomor dua di Andalusia, dinamakan orang dengan kota Damaskus di Barat atau "Damaskusnya Andalusia", karena banyak aneka buah-buah anggur, apel dan lain sebagainya. ${ }^{21}$

Di samping itu di Granada terkenal dengan arsitektur-arsitektur bangunannya di Erofa, seperti al-Hama yang merupakan istana yang indah dan megah serta dikelilingi taman-taman yang tidak kalah indahnya. ${ }^{22}$

\section{Aspek-aspek Peradaban yang paling Menonjol \\ Kemajuan Intelektual}

Masyarakat Islam Spanyol merupakan masyarakat yang majemuk yang terdiri dari komunitas-komunitas Arab (Utara dan Selatan). Maka mereka memberi saham intelektual terhadap terbentuknya lingkungan budaya Andalusia yang melahirkan kebangkitan ilmiah, sastra dan pembangunan.

a. Bahasa Arab

Ilmu pengetahuan berkembang dengan perantaraan bahasa Arab. Orangorang Andalusia baik muslim maupun non muslim menerima dan mempelajari bahasa Arab. Akibatnya lahirlah beberapa ahli bahasa Arab, diantaranya Ibnu 
Khuruf, Ibnu Al-Haji, Abu Hasan, ibnu Asfar, Abu Hayyan Al-Garnati dan Ibnu Malik yang mengarang kitab Alfiyah (buku tata bahasa Arab yang disusun dalam bentuk bait syair dan masih banyak lagi. ${ }^{23}$

b. Filsafat

Di Andalusia, filsafat Islam mencapai puncaknya dan filosof-filosof ini antara lain:

Ibnu Tufail (w. 1185) yang menulis buku Hayy Ibn Yaqzan (buku filsafat yang berisikan cerita seorang anak yang dipelihara oleh Rusa, filsafat akal dan wahyu.

Ibnu Bajah (w. 1138) yang dalam literatur Arab dikenal dega Avenpace dan merupakan komentator karya-karya Aristoteles, ahli fisika da ahli musik, karya utamanya adalah Tadbir Al-Matawahhid (susunan yang menyatu).

Ibnu Rusyd (1126-1198) yang memberikan jawaban atas serangan AlGhazali dalam ukunya tahafut At-Tahafut (kerancuan dari kerancuan) dan komentator terhadap karya Aristoteles Jami Talkhis (rangkuman yang lengkap). Karena pengaruhnya yang besar, di Eropa muncul suatu aliran filsafat yang dikenal dengan nama Averoisme. ${ }^{24}$ Dia juga ahli fiqih dengan karyanya Bidayah AlMujtahid. Di samping dikenal sebagai seorang ahli filsafat, fiqih, juga ia dikenal sebagai seorang astronomi dan dokter. Sumbangan Ibnu Rusyd yang terbesar kepada kedokteran adalah karangannya yang berupa ensiklopedia (Al-Kulliyyat fit Thibi). Dalam bukunya ini ia mengatakan bahwa tidak ada manusia yang mwndapatkan penyakit cacar dua kali. ${ }^{25}$ c. Sains

Di andalusia lahirlah orang-orang yang mempunyai keahlian dalam ilmu kedokteran, musik, matematika, astronomi, kimia dan lain-lain, seperti:

a. Abbas Ibn Farnas, termasyhur dalam ilmu kimia dan astronomi dan dia orang yang pertama mengemukakan pembuatan dari batu. ${ }^{26}$

b. Ibrahim ibnu Yahya Al-Naqqash terkenal dalam ilmu astronomi dan ia dapat menentukan terjadinya gerhana matahari.

c. Abu Ja'far Ahmad bin Muhamaad AlGafiqi (W. 1165) terkenal dalam bidang obat-obatan dengan karyanya Al-Adawiyah Al-Mufradah(uraian tentang berbagai macam obat). ${ }^{27}$

d. Ibnu Al-Khatib yang menyusun riwayat Granada (1311-1374).

d. Fiqih

Dalam bidang fiqih, terkenal dengan beberapa tokoh, antara lain: Abu Bakar Al-Qutiyah; Ibnu Hazm yang menulis kitab Al-Mushalla (tentang fiqih); Munzir bin Sa'id Al-Balluti (w. $355 \mathrm{H}$ ) yang pernah menjadi hakim agung di masa pemerintahan Abdurrahman III. 28

e. Tasawuf

Andalusia memiliki nama-nama dalam bidang tasawuf, seperti Muhyiddin Ibnu 'Arabi, sufi ternama yang menghasilkan banyak karya tulis antara lain, Al-Futuhat Al-Makyyah (Penaklukan Mekah) dan terkenal dengan paham Wahdagtul wujud (kesatuan wujud).

f. Musik dan kesenian

Dalam bidang musik dan seni suara, Spanyol Islam mencapai kecermelangan dengan tokohnya antara lain: Hasan Ibn Nafi yang dijuluki Zaryab. itulah sebagian dari kehebatan tokoh-tokoh yang pernah 
memberikan ilmunya pada dunia Islam, terutamna di Andalusia yang sebelum kedatangan Islam sangat terbelakang.

\section{Sumbangan Islam Bagi Peradaban Eropa}

Penduduk asli Andalusia disebut dengan bangsa Fandal dan bangsa Fandal yang sudah masuk Islam disebut Musta'riba / Muzarabes. kehiduapan sosial di Andalusia mencakup dua unsur pengembara. unsur pengembara di daerah Timur bersifat unsur pengembara telah mempunyai keterampilan bercocok tanam. ${ }^{29}$

Setelah Islam masuk ke Andalusia, maka mereka mengadakan asimilasi, di antaranya dengan cara perkawinan campuran antara wanita Andalusia dengan pria Arab. orang-orang Arab peranakan biasanya mempunyai namanama Arab dan mensilsilahkan keturunannya sebagaimana dilakukan orang Muslim lainnya di Timur. Dalam berbicara, mengenakan pakaian dan adat isti-adat yang biasa dipakai adalah kebiasaan, pakaian dan bahasa Arab. ${ }^{30}$

Dengan adanya asimilasi tersebut mengakibatkan adanya kesatuan untuk memajukan kota Andalusia. Sehingga banyak konstribusi Islam terhadap kebudayaan Eropa. Anadalusia merupakan tempat yang paling utama bagi Eropa menyerap peradaban Islam, Ekonomi, politik dan budaya.

Sumbangan Islam yang sangat menonjol dan menjadi dasar bagi kemajuan Barat antara lain dalam mbidang kedokteran:

1.Al-Kindi menulis buku ilmu mata

2.Ar-Razi menulis buku berjudul Al-Hawi 3.Ibnu Sina menulis buku Al-Qunun fi AlThib
4.Ibnu Rusyd menulis buku Kitab AlKuliyyat fi at-Thib.

Buku-buku tersebut menjadi referensi / pegangan bagi perguruanperguruan Eropa sampai akhir abad ke 15.31 Dalam bidang geografi muncul nama-nama cemerlang seperti al-Idrisi, Ibnu Abdul Aziz Al-Bahri (w.1094) dengan karyanya Al-Masalih wa AlMamalik. Abdul Hasan Muhammad bin Ahmad Al-Kinani bin Jubair (L. 1145) dengan karyanya Rihlah (suatu perjalanan). ${ }^{32}$

Dalam bidang fisika dikenal dengan nama Ibnu Zuhr, bidang mistik Ibnu 'arabi dan lain-lain, Eropa telah menyerap konstribusi-konstribusi intelektual dari orang-orang tersebut. ${ }^{33}$

- Az-Zarqali (L. 1029) di Taledo

- Abdul Qasim Maslama bin Ahmad Al-Farabi Al-Sasib Al-Majriti (w.1007)

di Cordova, yang merupakan ilmuan terkemuka muslim Andalusia angkatan peratama

- Jabir bin Aflah Abu Muhammad (w. 1204) di Sevilla yang menulis kitab Al-Hai'a, yang membuat angka-angka trigonometri yang masih digunakan sampai sekarang.

- Nuruddin Abu Ishak Al-Bitruji (w. 1204) yang menulis kitab Al-Hai'a.

Karya-karya para astronomi muslim ini telah banyak menyumbangkan istilah yang berasal dari bahasa Arab ke dalam perbendaharaan Ilmu astronomi dan matematika. ${ }^{34}$

Dalam bidang filsafat, filusuf Islam Ibnu Rusyd, Al-Kindi, Ibnu Tufail, ibnu Khaldun dan lain-lain, banyak memberikan sumabngan dan pengaruhnya di dunia Barat. 
1) Ibnu Rusyd dikenal sebagai komentator pikiran Aristoteles.

2) Al-Kindi adalah Filosof yang menggabungkan dalil-dalil Plato dan Aristoteles dengan cara Neo Platnis

3) Ibnu Khaldun dengan karya Muqaddimahnya memberikan sumbangan dan pengaruhnya dalam pemikiran-pemikiran sarjana-sarjana Barat di bidang ilmu sejarah dan sosiologi. 35

Jasa dan sumbangan Islam inilah yang kemudian mengubah wajah kebudayaan Eropa dan bahkan dunia pada umumnya, yakni :

1) Kebangkitan kembali (Renaissance) kebudayaan Yunani Klasik pada abad ke 14.

2) Gerakan pembeharuan agama kristen mulai abad ke- $8 \mathrm{M}$

3) Rasionalisme sebagai ekses dari rasionalitas Islam.

4) Pencerahan (Aufklarung,

Enlghtenment) pada abad ke- $18 .{ }^{36}$

\section{Sebab-sebab kemunduran dan}

\section{Kehancuran Andalusia}

Kemunduran umat Islam Andalusia di mulai ketika bani Umayyah di Cordova jatuh pada tahun 1030 M. ${ }^{37}$ kemunduran dan kehancuran Andalusia dapat dilihat dari dua hal :

1. Konflik antar umat Islam sendiri

Perpecahan yang ada pada umat Islam antara lain karena adanya sengketa antara saudara yang masing-masing ingin jadi raja dari suatu negara merdeka. Hasilnya tidak kurang dari 20 negara kecil-kecil yang berumu hanya seumur jagung timbul di kota-kota atau provinsi. Melihat perpecahan tersebut mengundang hastrat kaum Krosten di sebelah Utara untuk menyerang dan berusaha untuk merebut kembali daerah-daerahmereka. Perebutan itu dimulai ketika Bani Ummayyah Andalus runtuh dan terus menerus umat islam terdesak ke Selatan sehingga hanya tinggal Granada. ${ }^{38}$

Disamping itu orang-orang pribumi. Mereka masih memberi istilah 'ibad dan muwaladun kepada muallaf, yang ungkapan itu dinilai merendahkan. Akibatnya ntidak adanya ideologi yang dapat memberi makna persatuan dan mereka saling berperang dan bahkan diadu-domba oleh pihak ketiga. Sementara dinasti-dinasti kecil saling berperang, orang Kristen menyatuhkan diri untuk menaklukkan orang Islamdan menguasainya dari Andalusia. Secara politis kekuatan Islam berakhir pada penghujung abad ke-15 yang di tandai dengan kekalahan demi kekalahanm kerajhaan Islam.

2. Adanya Persatuan dari umat Kristen

Ketika umat Islam sedang dalam keadaan knflik, maka umat Kristen justru bersatu. Pada tahun 1969 kerajaan ferdinand dari Arogan dan kerajaan Isabella dari Castilia bersatu menyerang kekuatan islam dibawah kekuasaan dinasti Ahmar di Granada yang terkenal dengan Al-Hamra. Pada tanggal 2 januari 1492 / 12 Rabi'ul Awal 897 H, ibu kota Granada dikepung dan ditaklukkan oleh penguasa Kristen. ${ }^{39}$

Nasib Umat Islam dibawah Pemerintahan Kristen di Andalusia.

1. Pembatalan klausul-klausul pada perjanjian Grenada (899 H/1494 M)

Seluruh pemimimpin spanyol mulai membatalkan 66 klausul yang telah disepakati sebelumnya. yang terpenting diantaranya adalah: 
1. Seluruh masjid tetap dipertahankan dan tidak dirusak.

2. Tidak memasuki rumah orang muslim tanpa izin.

3. Setiap muslim tetap tinggal di tanahnya.

4. Seluruh kaum mislimin, baik anakanak maupun orang dewasa, mendapat jaminan keamanan. Tidak seorang kristenpun menguasai kaum muslim.

5. Kaum muslim bebas menjalankan ajaran agama mereka.

6. Tidak seorangpun muslim boleh membawa tanda apapun yang membedakannya dari orang Kristen dan yahudi.

7. Kaum tidak membayar pajak melebihi yang pernah mereka bayarkan kepada daulah mereka.

8. Mereka memilik hak untuk bepergian di penjuru spanyol

9. Tidak seorang muslim pun boleh dipaksa untuk memasuki agama Kristen dst.

Pada tahun 1498 M Setelah sepertiga juta muslim keluar dari spanyol, di sana banyak kaum muslim yang tidak mendapatkan cara untuk eksodus ke utara afrika dan mengaku beragam Kristen Karena takut disiksadi spanyol. Namun banyak dari kaum uslim tetap mempertahankan keislaman dan menjalankan syiar-syiar islam secara diam-diam. Hal itu sampai diketahui diktator Fernando, raja spanyol, lalu ia mengusir kaum muslim ke gununggunung sehingga mereka dimangsa binatang-binatang buas, mati kelaparan, atau diperbudak oleh orang-orang spanyol. Mereka berkelana atau bersembunyi di desa-desa dengan membayar uang suap.

2. Pengkristenan muslim Andalusia secara paksa (904 H/1499 M)

Orang spanyol lupa pada janji mereka. Dewan investigasi mengeluarkan instruksi kardinal cisneros untuk melakukan tindakan keras terhadap kaum muslim di spanyol dan bertindak cepat dalam mengkristenkan mereka secara paksa.

Mesjid Grenada diubah menjadi katedral, mushaf-mushaf dan kitab-kitab tafsir dan fiqih islam dibakar, kaum muslimin di berbagai tempat diusir, dan mereka dipaksa untuk, urtad dari islam.

3. Pemberontakan muslim Andalusia terhadap pemerintah Spanyol. (907 H/1502 M)

Kaum muslimin Andalusia melakukan pemberontakan untuk melawan kesewenang-wenangan pemerintah Ratu Isabella yang telah mengkhianati klausul klausul perjanjian.

Mereka memberontak di pegunungan al-Busyrah dan Gunung Merah. Mereka mengepung tentara Spanyol dan menghujani mereka dengan batu dari atas gunung sehingga ratusan tentara terbunuh, termasuk beberapa komandan Spanyol, seperti Fransisco Armez dan Alfonso Agulier. Ketika berita itu sampai ke Isabella, ia segera mengirim sebuah pasukan besar untuk mengepung pegunungan itu beserta para pemberontak di sana hingga mereka kelaparan dan terancam kematian. Pemberontakan yang telah berlangsung hampir 2 tahun berhasil meredam dan berakhir setelah Spanyol membiarkan kaum muslimin menyebrang ke Afrika Utara. 
Pada tahun 1508 M Kardinal Zamniz memperingatkan seluruh penduduk muslim agar menyerahkan buku-buku dan manuskrip-manuskrip yang ada di perpustakaan-perpustakaan mereka. Jika tidak mereka akan mendapat siksaan keras.

Dalam beberapa hari saja, kardianl telah mengumpulkan ribuan buku dalam berbagai bidang ilmu pengetahuan. Ia meilih buku-bukudan manuskripmanuskrip yang dianggapnya berguna membangun ilmu pengetahuan dan kebudayaan. Lalu ratusan ribu buku lainnya dibakar di sebuah lapangan terbuka di grenada, yang disebut Bab arRamallah. Pembakaran tersebut dipimpin oleh raja Spanyol dan para pendeta katolik.

Pada tahun 1521 M Penduduk Valencia memberontak terhadap raja Spanyol, Carlos. Raja tidak menemukan cara lain selain mengirim ribuan tentaranya untuk menumpas pemberontakan tersebut. Mereka membakar lahan- lahan pertanian, pusatpusat perdagangan dan sumber kehidupan kaum muslim di kota tersebut. Tentara Spanyol itu menyerang dan membantaikaum muslimin, serta merampas harta milik mereka. Carlos tak peduli, walaupun ia telah berjanji meleindungi mereka setelah membayar upeti.

4. Pembentukan Dewan Investigasi oleh Carlos $(933 \mathrm{H} / 1526 \mathrm{M})$

Dewan investigasi pertama dibentuk di Grenada atas perintah Raja Spanyol, Carlos, dengan tujuan untuk menyelidiki orang-orng islam yang pura-pura masuk kristen. Semua orang islam dipaksa agar jangan menggunakan bahsa arab, serta tidak boleh mengerjakan sholat, puasa, menggunakan nama Arab, berdo'a dengan do'a Islam atu menuburkan jenazah menurut syari'at Islam. Mereka jjuga dipaksa untuk minum khamar, memakan dagng babi dan bangkai, lakilaki tak boleh dikhitan dan orang mati harus dikuburkan menurut upacara agama Khatolik.

5. Pembakaran terhadap muslim (936 $\mathrm{H} / 1529 \mathrm{M}$ )

Penindasan terhadap kaum muslimin terus menungkat. Dewan yang sadis menghukum sekelompok kaum muslimin dengan cara dibakar hiduphidup diatas bara api yang menyala di salah satu sudut kota Grenada. Peristiwa tersebut dilakukan hanya untuk meneror kaum muslim diseluruh penjuru Spanyol.

6. Pelarangan syi'ar islam di Spanyol oleh Phillip II (975 H/1567 M)

Raja Panyol Phillip II, menuruti saran penasehatnya untuk mengkristenkan kaum muslimin dan melarang syai'at Islam. Ia mengeluarkan peraturan bahwa seluruh rumah kaum muslimin di Spayol harus terbuka, tanpa pintu, agar segala pekerjaan mereka yang berpura pura masuk kristen di dalamnya dapat terlihat. Kamar-kamar mandi yangn digunakan untuk berwudhu dihancurkan, penggunaan bahasa arab dalam bentuk apapun dilarang. Setiap upacara pernikahan, kelahiran, dan kematian harus disaksikan oleh wakil dari gereja khatolik. Walaupun demikian, kamum muslim tetap mampu mempertahankan agamanya.

7. Penyembelihan terhadap kaum muslimin $(979 \mathrm{H} / 1571 \mathrm{M})$.

Philip II memerintahkan tentaranya untuk menyembelih perempuan dan 
anak-anak Muslim sehingga lapanganlapangan terbuka di Grenada berubah menjadi lapangan pembantaian oleh komandan tentara Spanyol, Richwins, di hadapan kaum Muslimin yang lain. Adapun yang masih hidup di perbudak.

8. Pemberangkatan muslimin dari Aragon Valencia dan Wilayah sekitarnya (1019 H/1610 M)

13000 umat islam diberangkatkan dari Valencia ke afrika Utara. Peraturan tersebuut dilaksanakan secara paksa, dimana umat Islam dilarang membawa harta dan bekal milik mereka. Dan berangkat menggunakan kapal menuju pantai Afrika tanpa membawa pakaian, makanan ataupun minuman. Pembarangkatannya dilakasanakan 6 tahun berturut-turut.

Pemberangkatan dilakukan karena Pemerintah spanyol meras cemas akan bertambahnya umat islam di wilayah Valencia (timur Spanyol) dan kerjasama mereka, baik secara sembunyi- sembunyi maupun secara terang-terangan akan mengganggu pemerintahan Spanyol.

Pada tahun 1660 M, Pemerintah Spanyol diwilayah Aragon (terletak di timur laut Valencia yang berbatasan dengan prancis) mengikuti kebijakan Pemerintah Di Valencia sehingga mengusir 200.000 umat islam umat Islam.

Pengusiran Kaum muslimin tidak hanya pada daerah Grenada, Valencia, danAragon. Akan tetapi meliputi sebagian besar Spanyol dan Portugal. Kaum Muslimin yang meninggalkan rumah berkisar antara 500.000 hingga 3 juta. Namunjumlah yang sampai ke daerah tujuan di Afrika Utara dan Wilayah yang dikuasai pemerintah Utsmani di eropa selatan mencapai 4 juta jiwa. Mereka yang meninggal, terbunuh, atau tenggelam tidak kurang dari 60000 jiwa.

Pemberangkatan paksa tersebut berakhir pada masa raja Philip III. Kebijakan tersebut menyebabkan Spanyol kehilangan Penduduk yang giat dalam perekonomian

9. Pemberontakan ke-2 muslimin (1069 $\mathrm{H} / 1658 \mathrm{M})$

Para pemuda dan kaum Muslimin memberontak dan mengepung kota Grenada sehingga menimpakan kerugian besar menimpa kerugian besar terahadap pasukan keamanan di sana. Ketika kaum muslimin di desa-desa dan kota kota bertetangga mendengar adanya pemberontakan itu. Mereka turut ikut bergabung. Mereka datang dari lebih dari 20 kota dan desa, terutama wilayah busyrah (selatan grenada yang terbentang di laut mediterania)

Akhirnya pemerintah Spanyol berjanji akan mengkaji tuntutan mereka. Namun pasukan Spanyol tetap membantai dan memperkosa kaum wanita, manghancurkan rumah-rumah dan membakar lahan-lahan. Mendengar hal itu kaum muslimin kembal melakukan pemberontakan. Sehingga raja Spanyol menarik pasukannya di Italia untuk mengepung bukit-bukit yang merupakan tempat pemberontak selama beberapa bulan. Raja pun memerintah utuk menangakp setiap laki-laki muslim yang berusia 14 tahun. Dengan berlalunya waktu, para pemberontak semakin melemah akibat kekurangan air, makan dan persediaan senjata. Akhirnya berakhirlah pemberontakan terbesar kaum muslimin di Andalusia

Pada pertengahan abad empat belas, di Valensia posisi umat muslim semakin 
memburuk, muslim di bebani kewajiban finansial tambahan. Urusan kemiliteran di bebankan pada budak-budak muslim, sehingga menyebabkan penduduk muslim merdeka jatuh pada kelompok budak. Pada tahun 1311, raja James II melarang pengumandangan panggilan sholat (AZAN), meskipun pada tahun 1357 pengumandangan azan dengan suara tidak keras diperbolehkan dengan pembayaran tertentu.

Pada akhir abad empat belas, pihak kristen antusias terhadap upaya pengkristenisasi pemeluk Yahudi dan Muslim dan upaya penyerangan agama di Spanyol. Pada tahun 1391 umat Yahudi di paksa menerima Baptisme. Pada tahun 1479 program pemaksaan agama diresmikan, dan orang yahudi di minta memilih di antara Baptisme atau pengusiran.

Menandai awal berakhirnya sejarah warga Muslim di Spanyol. Meskipun terdapat perjanjian yang menjamin kebebasan beragama muslim dan harta mereka. Pada tahun 1501 perundangan Spanyol memaksa pihak muslim memilih di antara berpindah agama atau di keluarkan dari Spanyol. Pada 1556 pakaian arab dan muslim di larang beredar di Granada, dan pada 1566 Philip II mengeluarkan keputusan bahasa arab tidak boleh lagi digunakan. Akhirnya pada tahun 1609 Philip III mengusir umat muslim dari Spanyol. Mereka mengungsi ke Afrika Utara di mana warga Andalusia ini sekali lagi berperan dalam

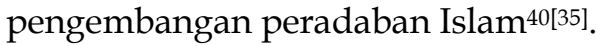

\section{Simpulan}

Islam pertama kali masuk ke Spanyol pada tahun $711 \mathrm{M}$ melalui jalur
Afrika Utara. Wilayah Andalusia yang sekarang disebut dengan Spanyol diujung selatan benua Eropa, masuk kedalam kekuasaan dinasti bani Umayah semenjak Tariq bin Ziyad, bawahan Musa bin Nushair gubernur Qairuwan, mengalahkan pasukan Spanyol pimpinan Roderik Raja bangsa Gothia (92 H/ 711 M). Spanyol diduduki umat islam pada zaman kholifah Al-Walid (705-715), salah seorang khalifah dari Bani Umayah yang berpusat di Damaskus.

Perkembangan Islam di Spanyol berlangsung lebih dari tujuh setengah abad. Perkembangan itu dibagi menjadi enam periode yaitu: Periode Pertama (711755 M), Periode Kedua (755-912 M), Periode Ketiga (912-1013 M), Periode Keempat (1013-1086 M), Periode Kelima (1086-1248 M), dan Periode Keenam (12481492 M). Kemajuan peradaban itu dipengaruhi oleh kemajuan intelektual yang di dalamnya terdapat ilmu filsafat, sains, fikih, musik dan kesenian, begitu juga dengan bahasa dan sastra, dan kemegahan pembangunan fisik.

Faktor-faktor pendukung kemajuan Spanyol Islam, diantaranya kemajuannya sangat ditentukan oleh adanya penguasapenguasa yang kuat dan berwibawa, yang mampu mempersatukan kekuatankekuatan umat Islam, seperti Abd alRahman al-Dakhil, Abd al-Rahman alWasith dan Abd al-Rahman al-Nashir.

Keberhasilan politik pemimpin-pemimpin tersebut ditunjang oleh kebijaksanaan penguasa-penguasa lainnya yang memelopori kegiatan-kegiatan ilmiah dan adanya toleransi yang ditegakkan oleh penguasa terhadap penganut agama Kristen dan Yahudi. 
kemunduran dan kehancuran Islam di Spanyol antara lain, konflik Islam dengan Kristen,tidak adanya Ideologi pemersatu, kesulitan ekonomi, tidak jelasnya sistem peralihan kekuasaan keterpencilan.

\section{Referensi}

${ }^{1}$ L.Stoddard, Dunia Baru Islam, Jakarta, 1966, h.24

${ }^{2}$ H.Zainal Abidin Ahmad, Ilmu Politik Islam IV: Sejarah Islam dan Umatnya, Jakarta: Bulan Bintang, 1978, h. 96

${ }^{3}$ Harun Nasution, Islam ditinjau dari Beberapa Aspeknya I, Jakarta : UI Press, 1985, h. 62

${ }^{4}$ Ensiklopedi Islam I, Jakarta : PT. Ichtiar Baru Van Houve, h. 145

${ }^{5}$ Hamka, Sejarah Umat Islam II, Jakarta: Bulan Bintang 1981, h. 134

'Yoesof Soy, Sejarah Daulah Umayyah di Corduva II, Jakarta : Bulan Bintang 1977, h. 9

${ }^{7}$ Ensiklopedi Islam, Op., cit., h. 146

${ }^{8}$ Badrai Yatim, Op., cit., Sejarah Pradaban Islam, Jakarta: PT. Raja Grafindo Persada, 1993, h. 94

${ }^{9}$ Ibid., h. 95

10Ibid., h. 96

11Ibid., h. 97

${ }^{12}$ Ensiklopedi Islam, Loc., cit.

${ }^{13}$ Badri Yatim, Op., cit., h. 98

14Ibid., h. 99

15Ibid., h. 100

${ }^{16}$ Musyrifah Sunanto, Sejarah Kebudayaan Islam: Perkembangan Intelektual Muslim, Jakarta : Perkasa, 1991, h. 72

17Hasil Kuliah dengan Dra. Musyrifah Susanto, th. 1991

${ }^{18}$ Harun Nasution, op., cit., h. 78

${ }^{19}$ A. Hasymy, Sejarah Kebudayaan Islam, Jakarta : Bulan Bintang, 1995, h. 203

20Ibid., h. 204

${ }^{21}$ Ibid

22Badri Yatim, Op., cit., h. 105

${ }^{23}$ Ensiklopedi Islam, Loc., cit

${ }^{24}$ Ensiklopedi Islam, Ibid

${ }^{25}$ Fuad Moh. Fahruddin, Perkembangan Kebudayaan Islam, Jakarta: Bulan Bintang 1984, h. 217

${ }^{26}$ Badri Yatim ., Op., cit., h.102

${ }^{27}$ Ensiklopedi Islam, Op., cit., h. 147

28Ibid., h. 146
${ }^{29}$ Muhammad Thohir, Sejarah Islam Dari Andalusia Sampai Hindustan, Jakarta: Pustaka Jaya, 1961,h. 384

${ }^{30} \mathrm{Ibid}$, h. 385

${ }^{31}$ Faisal Ismail, Paradigma Kebudayaan Islam, Yogyakarta : Titian Ilahi Press, 1996,h. 157

${ }^{32}$ Ensiklopedi Islam, Op., cit., h. 147

${ }^{33}$ Mehdi Nakosteen, Kontribusi Islam atas Dunia Intelektual Barat, terjemahan, surabaya, Risalah Gusti, 1996, h. 71

${ }^{34}$ Ensiklopedi Islam, Loc., cit.

${ }^{35}$ Faisal Ismail, Op., cit., h. 159

36S.I. Poeradisastra, Sumbangan Islam Kepada Ilmu dan Kebudayaan Modern, Jakarta : Girimukti Pusaka, 1978, h. 67

${ }^{37} \mathrm{H}$. Musyrifah Sunanto, Sejarah Kebudayaan Islam Dan Perkembangan Intelektual Muslim, Jakarta : Perkasa, 1991, h. 71

${ }^{38} \mathrm{Ibid}$, h. 72

${ }^{39}$ Ensiklopedi Islam, Op., cit., h. 148 